\title{
Mathematical Models for the Prediction of Coagulation Activity in Patients with Paroxysmal Atrial Fibrillation
}

\author{
Krasimira Prodanova, Mariya Negreva
}

\begin{abstract}
Our previous studies showed activation of coagulation in the early hours of the clinical manifestation of paroxysmal atrial fibrillation (PAF). Plasma coagulation activity of factor II, factor V, factor VII, factor VIII, factor IX, factor X, factor XI, factor XII, vWF, tissue factor levels, FVIII, vWF, prothrombin fragment $1+2(F 1+2)$ and fibrinopeptide $A$ (FPA) were significantly increased as early as the first twenty-four hours of the disease. The results suggest that there is a correlation between the studied parameters and development of the disease. Aim: To search for a statistical model that predicts coagulation activity in PAF patients. Materials and methods: Coagulation parameters were examined in 51 PAF patients (26 males, 25 females; mean age $59.84 \pm 1.60$ years, onset of PAF episode $<24 \mathrm{~h}$ prior to hospitalization). Controls included 52 individuals (26 males, 26 females; mean age $59.50 \pm 1.46$ years) with no prior anamnestic or ECG AF data, corresponding to patients in sex, age, BMI and comorbidities. A linear regression model was used to predict coagulation activity in PAF. Regression models showed good correlation between the duration of arrhythmia and six of the fourteen coagulation parameters studied: $F 1+2(r=0.83, p$ $<0.001)$, FPA ( $r=0.84, p<0.001)$, FVIII levels $(r=0.85, p<0.001)$ as well as activity of FII $(r=0.83, p<0.001)$, FVIII $(r=0.83, p$ $<0.001)$ and FXII $(r=0.78, p<0.001)$. Changes in $F 1+2$ plasma levels were most sensitive to PAF duration, where the contribution of duration to the values of the indicator is the greatest $(b=15.31)$. Conclusion: Linear regression analysis allowed us to create models with a high correlation coefficient for predicting the values of F1+2, FPA, FVIII levels, as well as activity of FII, FVIII and FXII in PAF patients. These models could allow for quantification of the procoagulatory process and thrombotic potential of the disease.
\end{abstract}

Keywords: coagulation, atrial fibrillation, predictive models.

\section{INTRODUCTION}

Atrial fibrillation (AF) is the most commonly diagnosed arrhythmia and it affects up to $3 \%$ of the total population [1, 2]. By the end of 2060, it is expected to affect around 18 million people in Europe and more than 12 million by 2050 in the USA [3]. AF is being increasingly referred to as the "current epidemic" of modern medicine [4]. One of the major clinical and socio-economic problems that AF causes are

Revised Manuscript Received on September 21, 2020.

Krasimira Prodanova, B.Sc: Technical University of Sofia, Faculty of applied mathematics and informatics, Sofia, Bulgaria; kprod@tu-sofia.bg

Mariya Negreva*, Department of Cardiology, Medical University of Varna, First clinic of cardiology, Varna University Hospital "St. Marina", Varna, Bulgaria; mnegreva@abv.bg

(C) The Authors. Published by Blue Eyes Intelligence Engineering and Sciences Publication (BEIESP). This is an open access article under the CC BY-NC-ND license (http://creativecommons.org/licenses/by-nc-nd/4.0/)
* Correspondence Author

thromboembolic events. As early as the beginning of the last century, Harvey and Levine found thrombosis in the left atrial appendage in the presence of atrial fibrillation, and in the 1970s, the Framingham study presented the first epidemiological data for an increased risk of stroke in patients with the disease [5, 6]. Today, the connection between them is undeniably accepted. It is estimated that about $30 \%$ of all strokes are associated with manifestation of AF, with longer hospital stays, higher disability and mortality in these cases [7]. Paroxysmal atrial fibrillation (PAF) accounts for about $30 \%$ of all AF cases, with some authors believing the percentage to be much higher and reaching up to $60 \%$ due to frequent asymptomatic course of the disease [8]. Only 1 in 12 paroxysms of AF are actually symptomatic in PAF patients [9]. Studies in populations with implanted pacemakers confirm the frequent asymptomatic course of the disease $[10,11]$. Despite its short duration and usually mild clinical course, PAF is associated with high incidence of embolic events [12, 13]. High morbidity and embolic risk arouse the interest in the coagulation changes occurring in PAF. The creation of mathematical models to determine coagulation activity in PAF patients would be a significant clinical contribution. This will allow for quantification of the coagulation process and thrombotic potential of the disease. At the same time, this could complement and expand the established embolic risk assessment scale for AF - the CHA2DS2-VASc score. Our previous studies showed that the clinical manifestation of PAF is associated with very early activation of the coagulation process [14-17]. We found that as early as the first twenty-four hours of the disease there was a significant increase in plasma coagulation activity of factor II (FII, p <0.001), factor V (FV, p <0.001), factor VII (FVII, $\mathrm{p}<0.001$ ), factor FVIII (FVIII, $\mathrm{p}<0.001$ ), factor IX (FIX, p <0.001), factor X (FX, p <0.001), factor XI (FXI, p $<0.001$ ), factor XII (FXII, p <0.001), vWF activity (p $<0.001$ ), as well as plasma levels of tissue factor (TF, $\mathrm{p}$ $<0.001$ ), FVIII ( $\mathrm{p}<0.05$ ), vWF ( $<<0.001$ ), prothrombin fragment $1+2(\mathrm{~F} 1+2, \mathrm{p}<0.001)$ and fibrinopeptide A (FPA, $\mathrm{p}<0.001$ ) in the studied patient population, compared to controls without prior arrhythmic data. This led us to assume that there is a relationship between the studied indicators and the development of the disease itself, and gave us the reason to conduct this study. All mentioned above formed our aim to analyze the established deviations in the fourteen coagulation indicators (presented above) in PAF patients in order to seek a statistical model for predicting procoagulant activity in the disease. 
Mathematical Models for the Prediction of Coagulation Activity in Patients with Paroxysmal Atrial Fibrillation

Table 1. Plasma levels and activity of the coagulation factors in patients with PAF and controls

\begin{tabular}{|l|l|l|l|}
\hline & $\begin{array}{l}\text { Patients } \\
\text { with PAF }\end{array}$ & Controls & P value \\
\hline FII activity (\%) & $167.81 \pm 9.12$ & $100.43 \pm 5.77$ & $P<0.001$ \\
\hline FV activity (\%) & $198.47 \pm 10.88$ & $121.53 \pm 4.79$ & $P<0.001$ \\
\hline FVII activity (\%) & $170.82 \pm 8.32$ & $95.17 \pm 5.26$ & $P<0.001$ \\
\hline FVIII activity (\%) & $200.03 \pm 11.11$ & $109.73 \pm 4.90$ & $P<0.001$ \\
\hline vWF activity (\%) & $200.92 \pm 12.45$ & $110.80 \pm 5.14$ & $P<0.001$ \\
\hline FIX activity (\%) & $170.43 \pm 6.62$ & $117.72 \pm 5.95$ & $P<0.001$ \\
\hline FX activity (\%) & $193.20 \pm 11.85$ & $116.20 \pm 5.86$ & $P<0.001$ \\
\hline FXI activity (\%) & $178.41 \pm 7.99$ & $111.75 \pm 5.50$ & $P<0.001$ \\
\hline FXII activity (\%) & $218.31 \pm 11.77$ & $148.41 \pm 7.48$ & $P<0.001$ \\
\hline TF levels pg/mL & $268.63 \pm 12.69$ & $170.21 \pm 9.18$ & $P<0.001$ \\
\hline FVIII levels (\%) & $107.52 \pm 4.36$ & $93.85 \pm 2.93$ & $P<0.05$ \\
\hline vWF levels (\%) & $178.40 \pm 12.95$ & $119.53 \pm 6.12$ & $P<0.001$ \\
\hline F1+2 plasma levels (pmol/L) & $292.61 \pm 14.03$ & $183.40 \pm 8.38$ & $P<0.001$ \\
\hline FPA plasma levels (ng/mL) & $4.47 \pm 025$ & $3.09 \pm 0.15$ & $P<0.001$ \\
\hline
\end{tabular}

\section{MATERIALS AND METHODS}

\section{Study population and design}

Coagulation indicators were examined in a population of 51 patients (26 males, 25 females; mean age $59.84 \pm 1.60$ years) with PAF onset $<24$ hours before hospitalization. Based on the inclusion and exclusion criteria (see below), they were sequentially selected from 338 patients admitted to the ward for the study period. 52 people (26 males, 26 females; mean age $59.50 \pm 1.46$ years) without anamnestic or ECG AF data were included as controls. We screened 169 volunteers for the selection and used the same exclusion criteria we applied to patients (see below).

Inclusion criteria (for the patient group):

1. Ability to clearly define the onset of arrhythmia, continuing at the time of hospitalization;

2. Lack of exclusion criteria.

Exclusion criteria:

1. cardiovascular diseases: ischemic heart disease, heart failure, high-grade and / or uncontrolled hypertension, moderate or severe acquired valve defects, cardiomyopathy, implanted device for the treatment of rhythm-conduction disorders, inflammatory heart disease, congenital heart diseases;

2. other diseases - kidney or liver failure, inflammatory and/or infectious diseases, neoplastic and autoimmune diseases, chronic pulmonary insufficiency, endocrine disorders (except for non-insulin dependent, well-controlled DM type 2); previous thromboembolic incidents, bleeding diathesis, miscarriages (for women);

3. intake of hormone replacement therapy, contraceptives, oral anticoagulants or antiplatelet drugs, pregnancy, systemic intake of analgesics (incl. NSAIDs), obesity with BMI >35;

4. unsuccessful restoration of sinus rhythm with drugs (propafenone) (for the patient group)

The parameters were examined once in plasma, obtained after centrifugation of peripheral venous blood. In patients, the blood sample was taken immediately after diagnosis in still persistent disease, and in controls during a conducted outpatient examination. The preparation, storage and examination of samples is duly described elsewhere [14-17].

The study was conducted in the Intensive Cardiology Unit of the First Cardiology Clinic at the University Hospital St. Marina - Varna for the period October 2010 - May 2012. It was initiated after written approval of the local Ethics Committee (No.9/14.10.2010) and was fully compliant with the requirements of the WMA Declaration of Helsinki, 2008 [18].

\section{Statistical analysis}

In the present study we applied simple linear regression to represent the observed coagulation changes in PAF as a function of time. We used the simple linear regression equation with one predictor (univariate regression analysis): $\mathrm{Yi}=\mathrm{a}+\mathrm{bXj}, \mathrm{i}=1,2$ and $\mathrm{j}=1,2,3$,

where $\mathrm{Yi}$ are the values of the dependent variable (in this case the coagulation indicator), $\mathrm{Xj}$ is the predictor (in this case the duration of atrial fibrillation), a is a constant or intercept of the regression line (i.e., the average of $\mathrm{Y}$, when $\mathrm{X}$ is 0 ), $\mathrm{b}$ - regression coefficient (slope), showing the average increase of the dependent variable when the factor variable is changed by one measure unit.

Based on the predicted and observed values of the indicators, we evaluated the adequacy of the models using the obtained correlation coefficient $\mathrm{R}$ and the adjusted correlation coefficient R2 of the model. The correlation coefficient $\mathrm{R}$ indicates a presence of a linear relationship between the dependent and the independent variable. The adjusted R2 coefficient of the corresponding indicator represents the proportion of the $\mathrm{Y}$ variance, which is related to or can be explained by the $\mathrm{X}$ variance, i.e. shows how much of the change in the values of this indicator can be explained by the change in the values of the predictor. It is one of the criteria for assessment of the adequacy of the regression model.

Continuous variables were expressed as mean \pm standard error of the mean (SE) and categorical variables were expressed as percentage of the total group. Normality of distribution was assessed by the Kolmogorov-Smirnoff test. Two-tailed Student's t-test for independent samples was used to compare quantitative variables. Fisher's exact test was used to compare categorical variables. Values $\mathrm{p}<0.05$ were adopted for statistically significant.

STATISTICA 13.3.0, StatSoft Inc, USA software package was used for all statistical analysis.

\section{RESULTS}

The obtained values for the coefficients $a$ and $b$ of the simple linear regression equation for each coagulation activity indicator are presented in Table 2.

Based on these, regression models were created to predict the values of the indicators depending on the duration of the rhythm disturbance (Table 3$)$.

F1 + 2 plasma levels $(r=0.83$, $p<0.001$; Fig. 1$)$, FPA $(r=$ 0.84, $p<0.001$; Fig. 2), FVIII ( $r=0.85, p<0.001$; Fig. 3 ) have a good correlation with arrhythmia duration, as well as FII coagulation activity ( $\mathrm{r}=0.83$, $\mathrm{p}<0.001$; Fig. 4), FVIII $(\mathrm{r}=$ 0.83, p <0.001; Fig. 5) and FXII ( $r=0.78$, p <0.001; Fig. 6) (Table 2). The positive value of coefficient $\boldsymbol{b}$ determines the direct proportionality between the values of these parameters and duration of arrhythmia (Table 2), i.e. an increase in PAF duration, increases indicator values increase. FXI activity has low correlation with disease duration $(r=0.39$, $p<0.001)$ (Table 2). The adjusted correlation coefficient $\mathrm{R}^{2}$ for the corresponding indicator indicates how much the change in the values of this indicator can be explained by the change in the arrhythmia duration.

Blue Eyes Intelligence Engineering

\& Sciences Publication

(C) Copyright: All rights reserved.

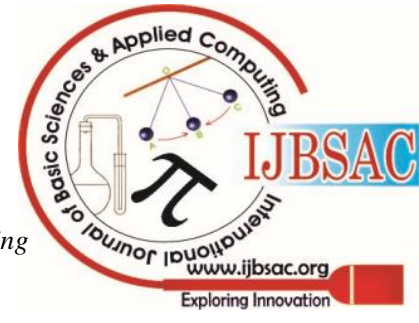


For example, for the F1+2 values, this coefficient is 0.67 , i.e. $67 \%$ of the change in $\mathrm{F} 1+2$ values are due to the change in arrhythmia duration. Accordingly, for FPA levels this percentage is $70 \%$, for FVIII - 72\%, for FVIII activity - 69\%, for FII activity - $67 \%$ and $61 \%$ for FXII activity. A very weak correlation was found between PAF duration and vWF levels $(\mathrm{r}=0.15, \mathrm{p}>0.05)$, vWF activity $(\mathrm{r}=0.13$, $\mathrm{p}>0.05)$, FV activity ( $\mathrm{r}=-0.11, \mathrm{p}>0.05$; Fig. 7 ), FVII activity ( $\mathrm{r}=$ $0.20, \mathrm{p}>0.05$; Fig. 8), FX activity $(\mathrm{r}=0.11, \mathrm{p}>0.05)$ and FXI $(r=0.20, p>0.05) . R^{2}$ was not applicable for these indicators.

Table2. Values of the estimated parameters of univariate regression models and the obtained correlation and adjusted determination coefficients.

\begin{tabular}{|c|c|c|c|c|}
\hline $\begin{array}{l}\text { Coagulation } \\
\text { marker }\end{array}$ & $\begin{array}{l}\text { a } \\
\text { p-value }\end{array}$ & $\begin{array}{l}\text { b } \\
\text { p-value }\end{array}$ & $\mathbf{R}$ & Adjusted R ${ }^{2}$ \\
\hline F1+2 plasma levels & $\begin{array}{l}167.68 \\
<0.001\end{array}$ & $\begin{array}{l}15.31 \\
<0.001\end{array}$ & 0.83 & 0.67 \\
\hline FPA plasma levels & $\begin{array}{l}.22 \\
<0.001\end{array}$ & $\begin{array}{l}0.28 \\
<0.001\end{array}$ & 0.84 & 0.70 \\
\hline FVIII levels & $\begin{array}{l}67.46 \\
<0.001 \\
\end{array}$ & $\begin{array}{l}4.91 \\
<0.001 \\
\end{array}$ & 0.85 & 0.72 \\
\hline FVIII activity & $\begin{array}{l}100.30 \\
<0.001\end{array}$ & $\begin{array}{l}12.23 \\
<0.001\end{array}$ & 0.83 & 0.69 \\
\hline vWF levels & $\begin{array}{l}198.97 \\
0.05 \\
\end{array}$ & $\begin{array}{l}-2.53 \\
0.30 \\
\end{array}$ & 0.15 & n.a. \\
\hline vWF activity & $\begin{array}{l}217.79 \\
<0.001\end{array}$ & $\begin{array}{l}-2.07 \\
0.38 \\
\end{array}$ & 0.13 & n.a. \\
\hline FII activity & $\begin{array}{l}86.62 \\
<0.001\end{array}$ & $\begin{array}{l}9.95 \\
<0.001 \\
\end{array}$ & 0.83 & 0.67 \\
\hline FIX activity & $\begin{array}{l}150.48 \\
<0.001 \\
\end{array}$ & $\begin{array}{l}2.45 \\
0.04 \\
\end{array}$ & 0.39 & 0.13 \\
\hline FV activity & $\begin{array}{l}211.23 \\
<0.001 \\
\end{array}$ & $\begin{array}{l}-1.57 \\
0.44\end{array}$ & 0.11 & n.a. \\
\hline FX activity & $\begin{array}{l}207.26 \\
<0.001 \\
\end{array}$ & $\begin{array}{l}-1.73 \\
0.44 \\
\end{array}$ & -0.11 & n.a. \\
\hline TF levels & $\begin{array}{l}245.53 \\
<0.001 \\
\end{array}$ & $\begin{array}{l}2.83 \\
0.24 \\
\end{array}$ & 0.17 & 0.01 \\
\hline FVII activity & $\begin{array}{l}189.01 \\
<0.001 \\
\end{array}$ & $\begin{array}{l}2.23 \\
0.15 \\
\end{array}$ & -0.20 & 0.02 \\
\hline FXII activity & $\begin{array}{l}118.84 \\
<0.001 \\
\end{array}$ & $\begin{array}{l}12.20 \\
<0.001\end{array}$ & 0.78 & 0.61 \\
\hline FXI activity & $\begin{array}{l}195.63 \\
<0.001 \\
\end{array}$ & $\begin{array}{l}-2.11 \\
0.15 \\
\end{array}$ & 0.20 & 0.02 \\
\hline
\end{tabular}

(n.a. - not available)

Table 3. Regression models for the values of the corresponding coagulation indicators as a function of the arrhythmia duration.

F1+2 plasma levels=167.68 + 15.31
FPA plasma levels $=2.22+0.28 \mathrm{X}$
FII activity $=86.63+9.95 \mathrm{X}$
FV activity $=211.23-1.57 \mathrm{X}$
FVII activity $=189.01+2.23 \mathrm{X}$
FVIII levels=67.46 $+4.91 \mathrm{X}$
FVIII activity $=100.30+12.23 \mathrm{X}$
vWF levels $=198.97-2.53 \mathrm{X}$
vWF activity $=217.79-2.07 \mathrm{X}$
FIX activity=150.48 $+2.45 \mathrm{X}$
FX activity $=207.26-1.73 \mathrm{X}$
FXII activity $=118.84+12.20 \mathrm{X}$
FXI activity $=195.63-2.11 \mathrm{X}$
TF levels $=245.53+2.83 \mathrm{X}$

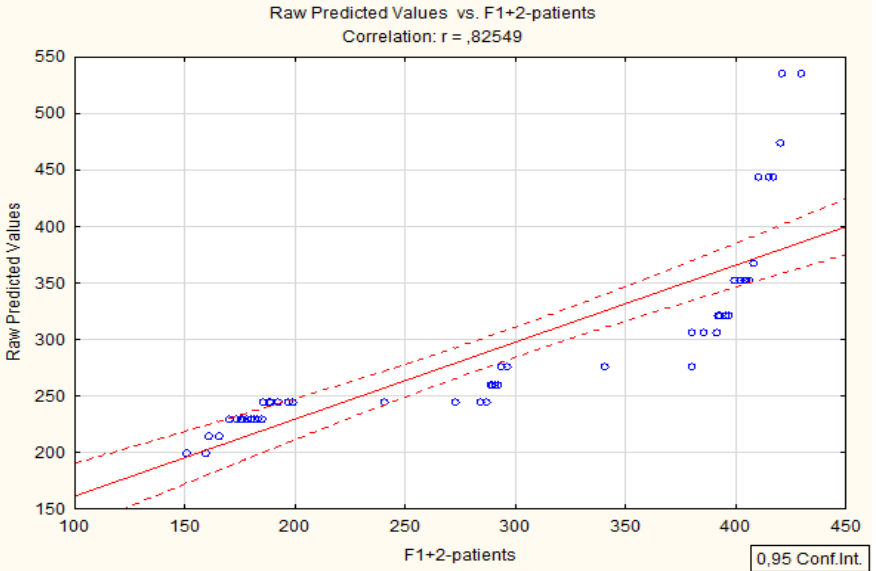

Figure 1. Scatter plot of measured versus predicted F1 + 2 plasma levels in PAF patients.

Raw Predicted Values vs. FPA.patients

Raw Predicted Values $=1,3265+, 70320^{\circ}$ FPApatients

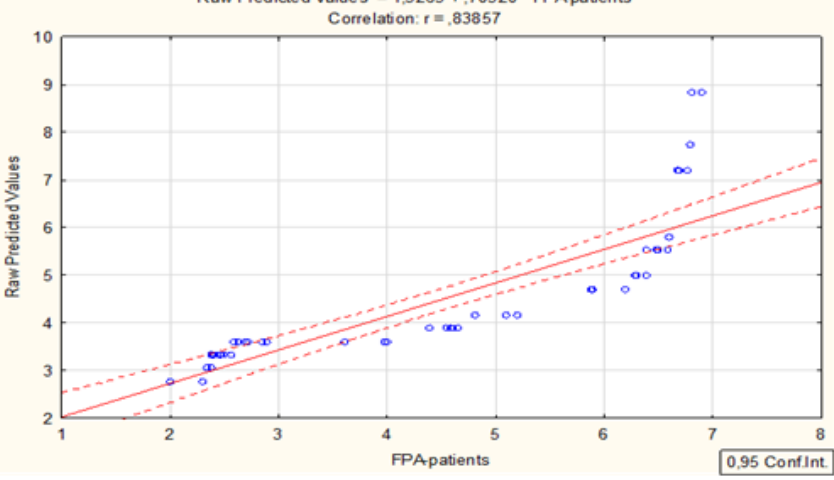

Figure 2. Scatter plot of measured versus predicted FPA plasma levels in PAF patients.

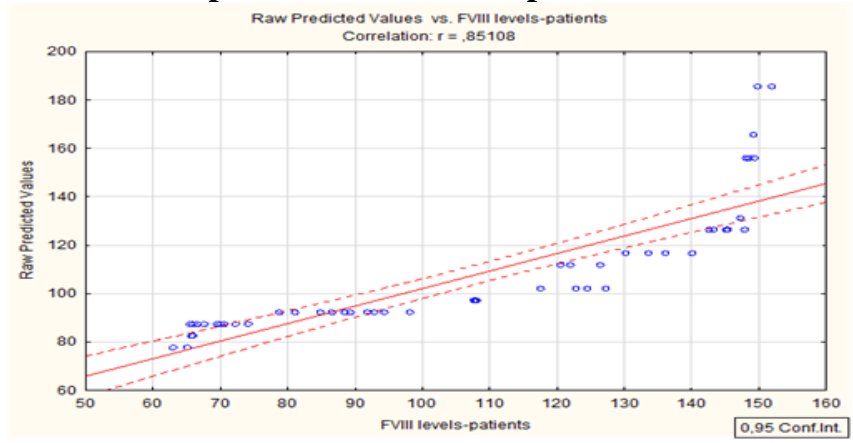

Figure 3. Scatter plot of measured versus predicted FVIII plasma levels in PAF patients.

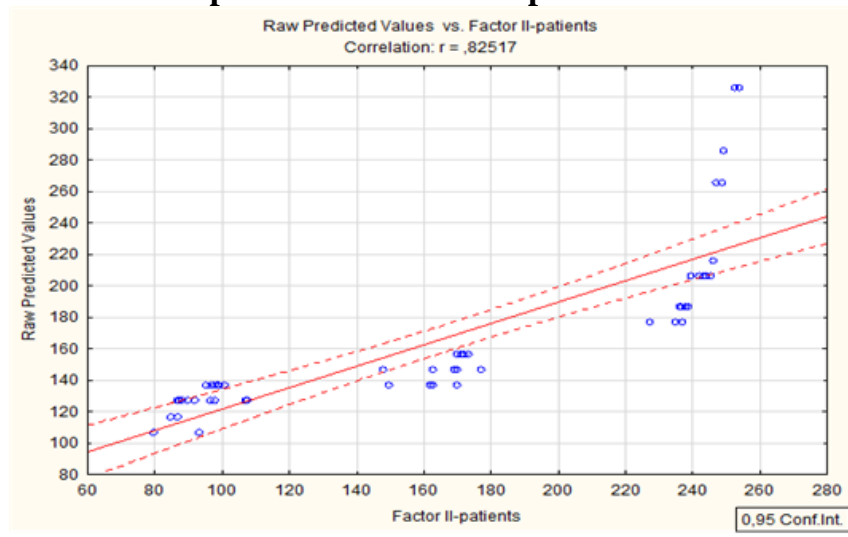

FIGURE 4. Scatter plot of measured versus predicted FII plasma levels in PAF patients.

Published By:

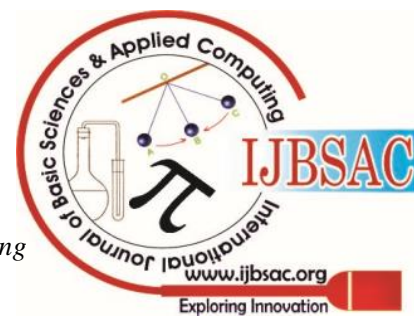




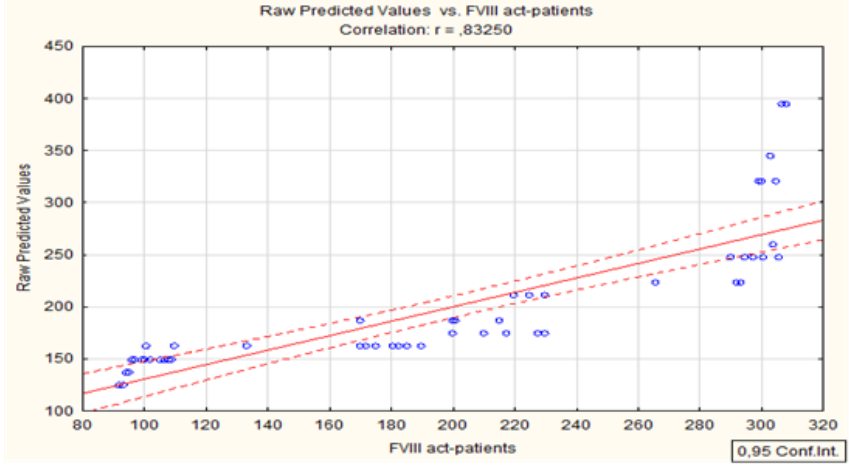

Figure 5. Scatter plot of measured versus predicted FVIII activity in PAF patients.

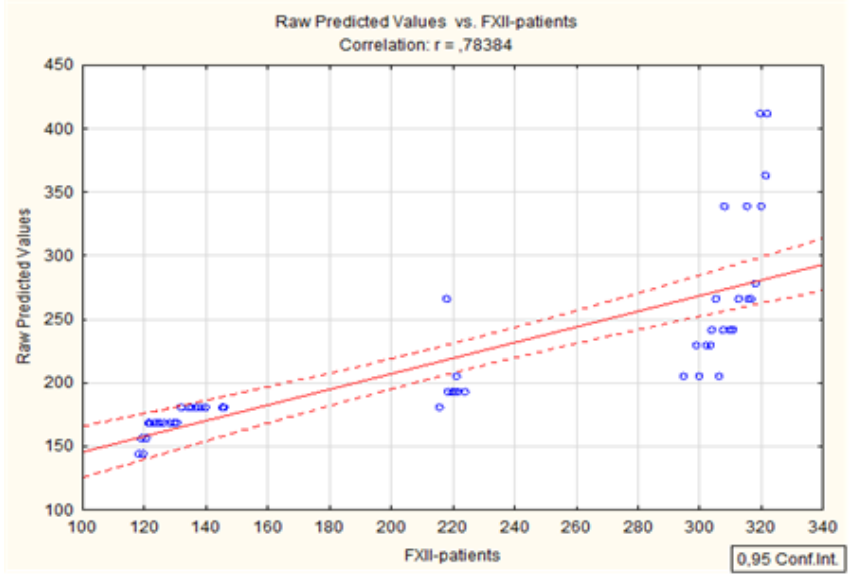

Figure 6. Scatter plot of measured versus predicted FXII activity in PAF patients.

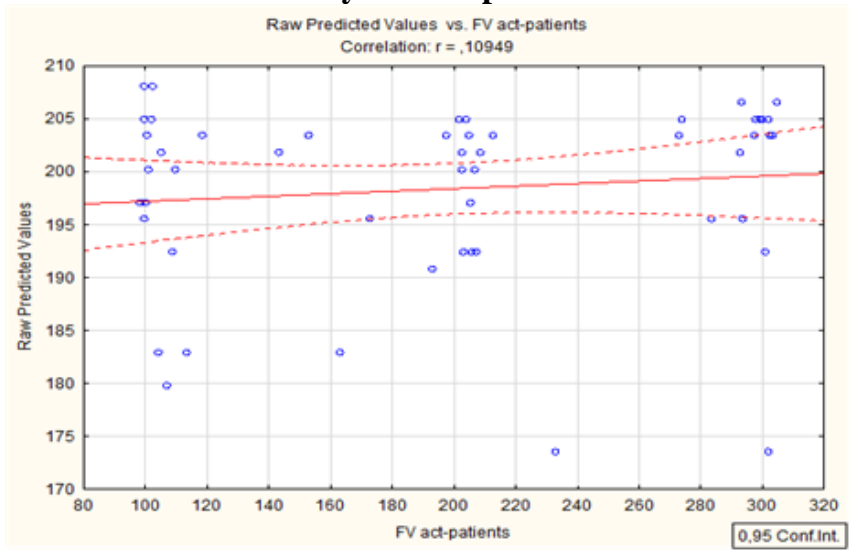

Figure 7. Scatter plot of measured versus predicted FXII activity in PAF patients.

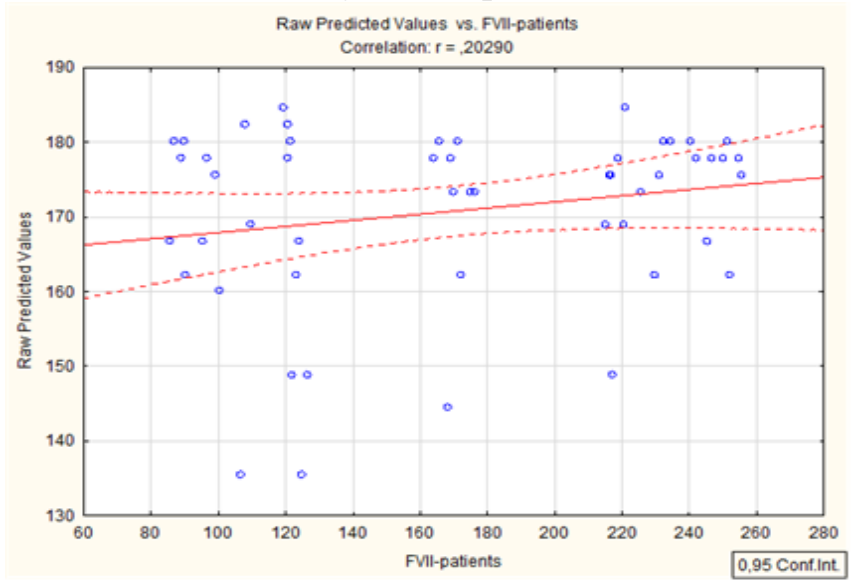

Figure 8. Scatter plot of measured versus predicted FVII activity in PAF patients.

\section{DISCUSSION}

Atrial fibrillation is associated with high risks of stroke or other thromboembolic events [7]. The pathophysiological mechanism associated with thrombus formation process is multifactorial [19]. Stasis in a poorly contracting left atrium has its own contribution, but in recent years there has been increasing evidence of hypercoagulation in AF [20-22]. Other studies have denied this [23, 24]. Of particular interest is the coagulation balance in PAF. Studies here are also controversial [25-27]. Our results showed significant activation of coagulation [14-17]. The statistical analysis showed no significant difference between the patient and the control group in terms of age and sex demographics, as well as in accompanying diseases and treatment, deleterious habits and BMI ( $>$ >0.05) (Table 4).

Table 4. Clinical characteristics of the participants.

\begin{tabular}{|c|c|c|c|}
\hline & $\begin{array}{l}\text { Patients } \\
\text { with PAF }\end{array}$ & Controls & $\begin{array}{l}\mathbf{P} \\
\text { values }\end{array}$ \\
\hline Number of participants & 51 & 52 & $\mathrm{p}=0.89$ \\
\hline Mean age (years) & $59.84 \pm 1.60$ & $59.50 \pm 1.46$ & $\mathrm{p}=0.87$ \\
\hline Men/Women & $26 / 25$ & $26 / 26$ & $\begin{array}{l}\mathrm{p}=1 / \\
\mathrm{p}=0.93\end{array}$ \\
\hline $\begin{array}{l}\text { Accompanying diseases } \\
\text { Hypertension } \\
\text { Diabetes mellitus type } 2 \\
\end{array}$ & $\begin{array}{l}37(72.54 \%) \\
3(5.88 \%) \\
\end{array}$ & $\begin{array}{l}34(65.38 \%) \\
2(3.84 \%)\end{array}$ & $\begin{array}{l}p=0.44 \\
p=0.62\end{array}$ \\
\hline Dyslipidemia & $4(7.84 \%)$ & $3(5.77 \%)$ & $\mathrm{p}=0.69$ \\
\hline $\begin{array}{l}\text { Medicaments for } \\
\text { Hypertension and Dyslipidemia } \\
\text { Beta blockers } \\
\text { ACE inhibitors } \\
\text { Sartans } \\
\text { Statins }\end{array}$ & $\begin{array}{l}19(37.25 \%) \\
15(29.41 \%) \\
11(21.57 \%) \\
4(7.84 \%)\end{array}$ & $\begin{array}{l}17(32.69 \%) \\
14(26.92 \%) \\
9(17.31 \%) \\
3(5.77 \%)\end{array}$ & $\begin{array}{l}\mathrm{p}=0.62 \\
\mathrm{p}=0.78 \\
\mathrm{p}=0.58 \\
\mathrm{p}=0.69\end{array}$ \\
\hline $\begin{array}{l}\text { Deleterious habits } \\
\text { Smoking } \\
\text { Alcohol intake }\end{array}$ & $\begin{array}{l}8(15.69 \%) \\
7(13.72 \%)\end{array}$ & $\begin{array}{l}7(13.46 \%) \\
6(11.53 \%)\end{array}$ & $\begin{array}{l}p=0.75 \\
p=0.74\end{array}$ \\
\hline BMI $\left(\mathrm{kg} / \mathrm{m}^{2}\right)$ & $23.85 \pm 0.46$ & $24.95 \pm 0.45$ & $\mathrm{p}=0.09$ \\
\hline $\begin{array}{l}\text { CHA }_{2} \text { DS }_{2}-\text { VASc score* } \\
\text { Patients with score }<2 \\
\text { Patients with score } \geq 2\end{array}$ & $\begin{array}{l}25 \\
26\end{array}$ & No score & \\
\hline
\end{tabular}

The equalization of the two groups makes the comparison between them in terms of coagulation indicators as objective as possible. It also makes it possible to take into account the effect of PAF itself on the studied indicators.

Regression analysis is a method of examining the functional dependency between variables, presented as an equation (model) linking the response or the dependent variable with one or more explanatory or predictor variables [28]. These characteristics of the regression analysis led us to seek models through which we could reliably predict the values of coagulation parameters depending on the arrhythmia duration in PAF patients. Correlation coefficient $\mathrm{R}$ and adjusted coefficient $\mathrm{R}^{2}$ are the main indicators of the adequacy of the created model. They show, respectively, the correlation strength and the proportion of changes in a given indicator that depend on the duration of the disease. Of the fourteen regression models presented above (Table 3), eight have a very weak correlation coefficient $(<0.2)$ and a statistically insignificant $\boldsymbol{b}$ coefficient ( $>>0.05)$. Only six of them are associated with a good correlation coefficient $(\mathrm{R}>$ 0.6), showing high correlation between the values of the corresponding coagulation indicator and PAF duration.

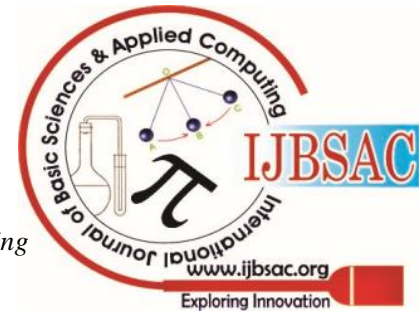


These are the models representing F1 + 2 plasma levels, FPA plasma levels, FVIII levels, FVIII activity, FII activity and FXII activity (Table 5). It is from these models that we expect good prediction of the time-varying coagulation indicators in PAF patients.

Table 5. Regression models of coagulation indicators in PAF with high correlation

$\mathrm{F} 1+2$ plasma levels $=167.69+15.31 \mathrm{X}$

FPA plasma levels $=2.22+0.28 \mathrm{X}$

FVIII levels $=67.46+4.91 \mathrm{X}$

FVIII activity $=100.29+12.23 \mathrm{X}$

FII activity $=86.63+9.95 \mathrm{X}$

FXII activity $=118.84+12.20 \mathrm{X}$

These models also showed a high, approximately the same, adjusted coefficient of determination $\mathrm{R}^{2}$, which is also indicative of the models' reliability (Table 2). Looking at the $\mathrm{F} 1+2$ model, $\mathrm{R}^{2}=0.67$ indicates that $67 \%$ of the total $\mathrm{F} 1+2$ plasma levels dispersion can be explained by the factor time dispersion (PAF duration). The remaining 33\% are due to factors not included in the model. Similarly with the models presented for FPA plasma levels, FVIII levels, FVIII activity, FII activity and FXII activity, we could explain 70\%, 72\%, $69 \%$ and $61 \%$ of the variance of the indicator as a result of time variance (Table 2).

In formulating conclusions about the quality of the linear model for predicting the values of Y (dependent variable), its coefficient $\boldsymbol{b}$ (determines the contribution of $\mathrm{X}$ in forming the values of $\mathrm{Y}$ ) is of major importance. The greater the value of $\boldsymbol{b}$, the greater the change in the dependent variable by changing the factor variable $\mathrm{X}$ with one measure unit. In this sense, of the six models with good correlation, the model for the plasma levels of $\mathrm{F} 1+2$, where $\boldsymbol{b}=15.31$, is the most impressive. It turns out that with a single unit change in the time of arrhythmia, the largest changes are expected in the values of this indicator. Changes in F1+2 plasma levels are most sensitive to PAF duration.

\section{CONCLUSION}

Linear regression analysis allowed us to create models with a high correlation coefficient for predicting the values of F1+2, FPA, FVIII levels, as well as the activity of FII, FVIII and FXII in PAF patients. These models could allow for quantification of the procoagulatory process and the thrombotic potential of the disease.

\section{ACKNOWLEDGEMENT}

The first author Krasimira Prodanova is supported by project DN12/11/20.dec.2017 of the Ministry of Education and Science of Bulgaria for statistical analysis of data.

Conflicts of interest

No conflicts of interest to declare.

\section{REFERENCES}

1. Chugh SS, Havmoeller R, Narayanan K, Singh D, Rienstra M, Benjamin EJ, et al. Worldwide epidemiology of atrial fibrillation: A Global Burden of Disease 2010 study. Circulation. 2014;129:837-47.

2. Go AS, Mozaffarian D, Roger VL, Benjamin EJ, Berry JD, Blaha MJ, et al. Heart disease and stroke statistics-2014 update: A report from the American Heart Association. Circulation. 2014;129:e28-92.
3. Krijthe BP, Kunst A, Benjamin EJ, et al. Projections on thenumber of individuals with atrial fibrillation in the EuropeanUnion, from 2000 to 2060. Eur Heart J 2013; 34: 2746-2751.

4. O'Donnell MJ, Chin SL, Rangarajan S, Xavier D, Liu L, Zhang H, et al. Global and regional effects of potentially modifiable risk factors associated with acute stroke in 32 countries (INTERSTROKE): A case-control study. Lancet. 2016;388:761-75.

5. Harvey EA, Levine SA. A study of uninfected mural thrombi of theheart. Am J Med Sci. 1930;180:365.

6. Wolf PA, Abbott RD, Kannel WB. Atrial fibrillation as an independentrisk factor for stroke: the Framingham Study. Stroke. 1991;22:983-988.

7. Marini C,De Santis F, Sacco S, Russo T, Olivieri L, Totaro R, CaroleiA. Contribution of atrial fibrillation to incidence and outcome ofischemic stroke: results from a population based study. Stroke 2005;36: 1115-9.

8. Zoni-Berisso M, Lercari F, Carazza T, Domenicucci S. Epidemiology of atrial fibrillation: European perspective. Clin Epidemiol. 2014;6:213-220.

9. Page RL, Wilkinson WE, Clair WK, McCarthy EA, Pritchett EL.Asymptomatic arrhythmias in patients with symptomatic paroxysmalatrial fibrillation and paroxysmal supraventricular tachycardia. Circulation. 1994; 89: 224-7.

10. Chu SY, Jiang J, Wang YL, Sheng QH, Zhou J, Ding YS.Pacemaker-detected atrial fibrillation burden and risk of ischemic stroke or thromboembolic events-A cohort study. Heart Lung. 2020;49(1):66-72.

11. Chen LY, Chung MK, Allen LA, Ezekowitz M, Furie KL, McCabe P et al. Atrial Fibrillation Burden: Moving Beyond Atrial Fibrillation as a Binary Entity: AScientific Statement From the American Heart Association. Circulation. 2018;137(20):e623-e644.

12. Ganesan AN, Chew D, Hartshorne T,Selvanayagam JB2, Aylward PE, Sanders P, McGavigan AD.The impact of atrial fibrillation type on the risk of thromboembolism, mortality, and bleeding: a systematic review and meta-analysis. Eur Heart J. 2016;37(20):1591-602.

13. Friberg L, Hammar N, Rosenqvist M.Stroke in paroxysmal atrial fibrillation: report from the Stockholm Cohort of Atrial Fibrillation.Eur Heart J. 2010;31(8):967-75.

14. Negreva M, Zarkova A, Prodanova K, Petrov P. Paroxysmal Atrial Fibrillation: Insight Into the Intimate Mechanisms of Coagulation. Cardiol Res. 2020;11(1):22-32.

15. Negreva MN, Prodanova K, Vitlianova K, Madjova C. Paroxysmal atrial fibrillation: changes in factor VIII and von Willebrand factor impose early hypercoagulability. Archives of Medical Science Atherosclerotic Diseases. 2020;5(1):140-147.

16. Negreva MN, Prodanova KS, Vitlianova KD. Paroxysmal atrial fibrillation is associated with early coagulation activity regardless of risk factors for embolism [published online ahead of print, $2020 \mathrm{Jul} \mathrm{10].}$ Minerva Cardioangiol. 2020;10.23736/S0026-4725.20.05209-3.

17. Negreva M, Prodanova K, Zarkova A. Paroxysmal atrial fibrillation : an independent risk factor for prothrombotic conditions [ahead od printing]. Journal of Atrial Fibrillation. 2020;12(7).

18. World Medical Association Declaration of Helsinki (2008). Ethical principles for medical research involving human subjects. 59th WMA General Assembly. Seoul.

19. Watson T, Shantsila E, Lip GY. Mechanisms of thrombogenesis in atrial fibrillation: Virchow's triad revisited.Lancet. 2009; 373:155-166.

20. Lip GY, Lip PL, Zarifis J, Watson RD, Bareford D, Lowe GD, et al. Fibrin D-dimer and beta-thromboglobulinas markers of thrombogenesis and platelet activation in atrial fibrillation. Effects of introducingultra-low-dose warfarin and aspirin. Circulation. 1996; 94:425-431.

21. Colkesen Y, Acil T, Abayli B, Yigit F, Katircibasi T, Kocum T, et al Mean platelet volume is elevated during paroxysmal atrial fibrillation: a marker of increased platelet activation? Blood Coagul Fibrinolysis.2008; 19:411-414.

22. Fu R, Wu S, Wu P, Qiu J. A study of blood soluble P-selectin, fibrinogen, and von Willebrand factor levelsin idiopathic and lone atrial fibrillation. Europace. 2011; 13:31-36.

23. Choudhury A, Chung I, Panja N, Patel J, Lip GY. Soluble CD40 ligand, platelet surface CD40 ligand,and total platelet CD40 ligand in atrial fibrillation: relationship to soluble P-selectin, stroke risk factors, and risk factor intervention. Chest. 2008; 134:574-581.

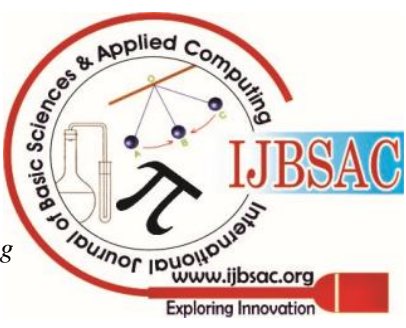




\section{Mathematical Models for the Prediction of Coagulation Activity in Patients with Paroxysmal Atrial Fibrillation}

24. Marin F, Roldan V, Lip GY. Fibrinolytic function and atrial fibrillation. Thromb Res. 2003; 109:233-240.

25. Giansante C, Fiotti N, Miccio M, Altamura N, Salvi R, Guarnieri G. Coagulation indicators in patients with paroxysmal atrial fibrillation: effects of electric and pharmacologic cardioversion. Am Heart J. 2000;140(3):423-9.

26. Sohara H, Miyahara K. Effect of atrial fibrillation on the fibrino-coagulation system--study in patients with paroxysmal atrial fibrillation. Jpn Circ J. 1994;58(11):821-6.

27. Kamath S, Blann AD, Chin BS, Lip GY. Platelet activation, haemorheology and thrombogenesis in acute atrial fibrillation: a comparison with permanent atrial fibrillation. Heart. 2003;89(9):1093-1095.

28. Jobson J. Applied Multivariate Data Analysis: Regression and Experimental Design. New York: Springer-Verlag; 1991. 622 p.

\section{AUTHORS PROFILE}

Prof. Krasimira Prodanova, PhD Personal details: 1972 - 1976 BSc (Faculty of Mathematics, Informatics and Mechanics) University of Sofia, Bulgaria; 1976 - 1978 MSc (Differential Geometry) University of Sofia, Bulgaria; 1995 - PhD (Theory of Probability and Statistcs - thesis title: Statistical Models in pharmacokinetics) University of Sofia, Bulgaria. Employment history and experiences: 2007 - present; Previous Appointments: 1980-1987 Senior Biostatisticians (Bulgarian Academy of Medicine, Faculty of Pharmacy); 1987-1999: Assistant Professor (TU-Sofia, Faculty of Applied Mathematics\&Informatics, Department of Statistics\& Optimization); 2000- Present: Professor; 2000 - 2004: Head of Department "Statistics \& Optimization". Scientific Publications: above 9, more of them with Impact Factor; Research Interests include mathematical modeling in pharmacokinetics and medicine, estimation of the parameters of stochastic models, drug response models, survival analysis and optimization problems.

Assoc. Prof. Mariya Negreva, MD, PhD graduated from Medical University of Varna,Bulgaria in 2006. Since 2008 Negreva has been working as assistant professor in Intensive Care Unit at University hospital of Varna, Bulgaria; since 2013 has been a specialist in cardiology and echocardiography. In 2015 - completed her PhD. 2016 - present assoc. prof. in First clinic of cardiology, University hospital of Varna, Bulgaria. Her research area is atrial fibrillation and echocardiography. Member Of Bulgarian Society Of Cardiology, Euripean Society of Cardiology.

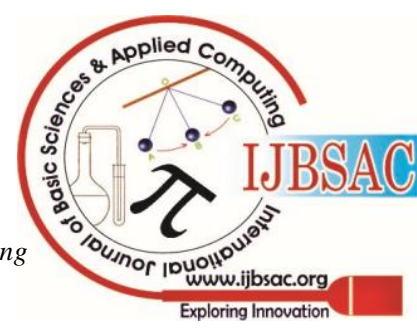

